\title{
Planning Education in Accessible Transport for Persons with Disabilities
}

Mahtot Gebresselassie

Keywords: accessible mobility, transport for persons with disabilities, transport-planning education

https://doi.org/10.32866/7029

\section{Transport Findings}

This study looks at whether the 1990 Americans with Disabilities Act is reflected in transport-planning education. It examines how planning schools prepare students, if at all, to work effectively in a system that aims to respond to transport needs of persons with disabilities. A survey of transport-related courses in graduate planning programs in US universities was conducted. The research question is: What is the state of planning education related to accessible transport? Findings show coverage of the topic to be minimal in programs surveyed. The purpose of the study is to raise questions of transport accessibility for persons with disabilities.

\section{RESEARCH QUESTION AND HYPOTHESIS}

Transport planning education should provide students with knowledge of various transport topics: the ability to work with the public, an understanding of the political context they will work in, and technical and technological skills required for practice (Khisty and Kikuchi 2003; Handy et al. 2002; Turnbull 1993; Wu et al. 2014). Changes in transport technology, demographic trends, and the political climate affect transport planning. Planning education should train students on par with these changes. In her seminal work, (Turnbull 1993) identified the Americans with Disabilities Act as one of the policy initiatives that could impact transport planning and highlighted the need for university education to respond to it.

This study examines whether ADA requirements are reflected in transport planning education by asking: What is the state of planning education in accessible transport for persons with disabilities (accessible transport hereafter) in US universities? To date, no study has focused on this topic. The majority of work in transport planning education has examined the curriculum in general, with a few studies looking at specific topics (Krizek and Levinson 2005; Wu et al. 2014). Mentions of the ADA in topics taught in transport planning education appear in a few studies (Zhou and Schweitzer 2009; Handy et al. 2002), which report the extent of coverage of ADA-related themes to be among those receiving the least attention. 
Table 1: Terms of Content Analysis

\begin{tabular}{lll}
\hline Key Terms Listed for Analysis & Key Terms Identified in Syllabi & Related Themes Identified in Syllabi \\
Disabilities & Universal design & Disadvantaged populations \\
Universal design & Paratransit, paratransit systems & Equity \\
$\begin{array}{l}\text { Accessible transport } \\
\text { Seniors, senior mobility }\end{array}$ & Elderly/disabled transport & Sustainable transport \\
Paratransit & Age and travel & Social justice \\
ADA & Persons with disability & Vulnerable populations \\
& Transport and aging population & Walkable streets \\
Note: "Key terms" listed for analysis and identified in syllabi review refer to terms that are particular to disability and mobility limitation, while "related themes" \\
\end{tabular}

\section{METHODS AND DATA}

The study followed similar approaches to that of previous research examining transport planning education (Turnbull 1993; Handy et al. 2002; Khisty and Kikuchi 2003; Wu et al. 2014). A survey was conducted on transport-related courses offered in a list of 51 graduate urban planning programs which specialize or have a concentration in transport and a list of 44 that do not. The lists were generated from the 2014 Planetizen Guide (Steins et al. 2017). Directors of each academic program were contacted using the information found on the Association of Collegiate Schools of Planning member list and respective websites. The names and contact information of professors who taught transport-related courses in the last three years were requested from each school. This enabled each department to determine what they would consider transport-related courses for their respective programs. Professors were requested to share their syllabi.

The syllabi were analyzed for content referring to accessible transport. The terms listed in the first column of Table 1 are commonly used words related to disability and limited mobility. Course coverage of accessible transport was evaluated by their presence. Thematic terms listed in the final column were identified during the review of the syllabi. Their presence was considered an indication of possible coverage of the topic of interest; a thorough review of syllabi was conducted even in the absence of the key terms in the left column. The review included course title, learning objectives, topics covered in each class, assignments/projects, and required and suggested readings. Once the topic of interest was identified, extent of coverage was determined. (See Table 2 for criteria and coverage.)

\section{FINDINGS}

Using the aforementioned outreach method, 53 course syllabi from 23 programs were collected. Five programs out of the second list reported that (a) they no longer offer transport courses, (b) they do not offer transport courses at master's level, or (c) their planning programs have been disbanded. Only one course syllabi out of the 53 indicated full coverage of accessible transport. One 


\begin{tabular}{lll}
\hline Extent of Coverage & Frequency & Percentage \\
No $^{a}$ & 44 & $83 \%$ \\
Minor $^{b}$ & 7 & $13 \%$ \\
Major $^{c}$ & 1 & $2 \%$ \\
Full course $^{d}$ & 1 & $2 \%$ \\
Total & 53 & $100 \%$ \\
& & \\
${ }^{a}$ No mention of the topic. & & \\
${ }^{b}$ Mention of the topic in less than three class sessions. & & \\
${ }^{c}$ More than three class sessions. & & \\
${ }^{d}$ Topic is the sole or main subject of the course. &
\end{tabular}

course showed major coverage, seven showed minor coverage, and 44 syllabi did not reflect any of the selected keywords. The course fully dedicated to accessible transport looked at design of walkable streets with respect to seniors. The only course in the "major" category looked at demand-responsive transport for persons with disabilities in addition to that of the general public. The seven courses identified in the "minor" coverage category were listed as universal design, paratransit, paratransit systems and elderly/disabled transport, age and travel, persons with disabilities (in relation to street design), transport and aging population, and age and disability. However, it can be gleaned from course syllabus that the overall extent of coverage of accessible transport in the surveyed syllabi was very low, consistent with findings of previous work looking at transport topics.

The study also found topics in the syllabi that encompass accessible transport, topics such as sustainable transport, equity, and disadvantaged communities. However, the study of disadvantaged communities focused on issues resulting from low income. Topics in social equity explored environmental justice. Complete streets, active transport, and similar topics were in reference to cycling and walking for the general public. Nonetheless, the higher degree of coverage of such topics could imply a possible discussion regarding accessible transport that takes place in these courses but was not reflected in the language of course syllabi. Moreover, it highlights ample opportunities to incorporate the topic of interest, at an introductory level, without major modifications to existing syllabi. With various courses and topics to offer in a limited amount of time, each program will have to make its own priorities based on student and faculty interests. As (Sussman 2005) stated, "each individual academic program seeks a balance appropriate to its institutional mission" (p. 94). One limitation of the study is the fact that it relies on the language of course syllabi, which varies in degree of detail about course coverage. It is also important to note that the findings are limited to the participating 23 programs.

Based on the analysis, two options to incorporate these topics into any curriculum are suggested (a) as a full-course option dedicated to the topic and (b) as a major-component option that is part of a course that teaches similar 
topics (such as transport equity for disadvantaged groups). In both options, it is recommended that the topic be introduced in other transport planning courses (e.g., in a transport policy course, in the form of one class, part of a class, or as one project topic). The full-course option can be offered in varying credit hours by organizing content in modules. (See supplementary material for a sample, full-course option.) 


\section{REFERENCES}

Handy, Susan, Lisa Weston, Jumin Song, and K. Maria D. Lane. 2002. "Education of Transportation Planning Professionals." Transportation Research Record: Journal of the Transportation Research Board 1812 (1): 151-60. https://doi.org/10.3141/1812-19.

Khisty, C. Jotin, and Shinya Kikuchi. 2003. "Urban Transportation Planning Education Revisited: Reading the Dials and Steering the Ship." Transportation Research Record:Journal of the Transportation Research Board 1848 (1): 57-63. https://doi.org/10.3141/1848-08.

Krizek, Kevin, and David Levinson. 2005. "Teaching Integrated Land Use-Transportation Planning." Journal of Planning Education and Research 24 (3): 304-16. https://doi.org/10.1177/ $\underline{0739456 x 04267731 .}$.

Steins, C., A. Chavan, Planetizen Press, and Urban Insight (Firm). 2017. Planetizen Guide to Graduate Urban Planning Programs. 5th ed. Los Angeles, CA: Planetizen Press.

https://store.planetizen.com/collections/guide-to-graduate-urban-planning-programs.

Sussman, J.M. 2005. "Educating the 'New Transportation Professional." In Perspectives on Intelligent Transportation Systems (ITS), 88-99. New York: Springer.

Turnbull, K.F. 1993. "An Analysis of Graduate Transportation Planning Education in the United States.” Texas A\&M University, College Station.

Wu, Yen-Chun J, Chung-Cheng J Lu, Taih-Cherng Lirn, and Chih-Hung Yuan. 2014. "An Overview of University Level Sustainable Transportation Curricula in North America and Europe." Transportation Research Part D: Transport and Environment 26 (January): 27-31. https://doi.org/10.1016/j.trd.2013.10.006.

Zhou, Jiangping, and Lisa Schweitzer. 2009. "Transportation Planning Education in the United States." Transportation Research Record: Journal of the Transportation Research Board 2109 (1): 1-11. https://doi.org/10.3141/2109-01. 


\section{FIGURES, TABLES, AND SUPPLEMENTARY MATERIALS}

\section{Supplementary Material}

Download: https://transportfindings.org/article/7029-planning-education-in-accessible-transport-forpersons-with-disabilities/attachment/17905.pdf 